\title{
Lissencephaly-1 gene is required for establishment of axis formation in drosophila melanogaster
}

\author{
Shereen A.M. Mohamed ${ }^{1}$; Ibrahim I.S. El. Shawaf ${ }^{1}$; Abd El Wahab M. Hassan ${ }^{1}$;Hoda A.S. Elgarhy ${ }^{1}$ and \\ Kh. Fahmy ${ }^{2 *}$ \\ ${ }^{1}$ Dept. of Genetics and Genetic Engineering, Faculty of Agric., Benha University, Moshtohor, Egypt. \\ ${ }^{2}$ Dept. of Genetics, Faculty of Agric., Ain Shams University, Cairo, Egypt \\ * Corresponding author: khalid.fahmy@med.lu.se, fahmy_kh@yahoo.com
}

\begin{abstract}
Lissencephaly-1gene is known to play many roles during drosophila development, it regulates cyst division, oocyte nucleus migration and control germ stem cell self-renewal hence oocyte formation. In this study we investigated the differential expression of $U A S$ lis-1 RNAi gene construct under the effect of five GAL4 drivers (Nos GAL4, Nub GAL4, Eve 3+7 GAL4, Kni GAL4, Ftz GAL4)on cuticle development. Results showed that Nos and Nub GALA/UAS lis-1 RNAi have strong effect on abdominal segment development. Meanwhile, Eve 3+7, Kni and Ftz GAL4/UAS lis-1 RNAi showed moderate effect. Proteomic studies (protein- protein interaction) using bicoid (bcd) and even-skipped antibody were used for determining the effect of Nos GAL4/UAS lis-1 RNAi on the expression of maternal and zygotic genes during developmental process. Results showed that Nos GAL4/UAS lis-1 RNAi gene affected slightly on the distribution of the bicoid protein. On the other hand using even-skipped antibody showed alteration in the head length and stripe pattern comparing with control. The overall data showed that UAS lis-1 RNAi gene play an essential role in drosophila axis formation and can be considered as a zygotic effect.
\end{abstract}

Key words: Drosophila, Lissencephaly-1gene, ectopic expression, anterior-posterior polarity, Segmentation, protein-protein interaction, Axis formation.

\section{Introduction}

Comparative analysis of whole genomes revealed striking similarities between structural composition of human and Drosophila genes (Rubin et al., 2000). Therefore, Drosophila melanogaster is considered one of the important model systems to study biological pattern formation and body plan scaling (Umulis and Othmer, 2013). It is used as a prime model organism for experimental studies of multicellular eukaryotic biology and it combines genetic, anatomic, behavioral and methodical because of its well-known genetics and wide varieties of techniques (Adams et al., 2000). One of the most important genetic systems used in reverse genetic approaches in Drosophila is the upstream activation sequence UAS/ GAL4 system (Brand and Perrimon 1993). This system involves a cross between a fly expressing GAL4 in particular cells and a fly carrying a gene of interest under the transcriptional control of the GAL4 upstream activating sequence, or UAS. In the progeny of such across, the gene of interest will be expressed in cells where GAL4 is synthesized at $29^{\circ} \mathrm{C}$ (Brand and Perrimon 1992).During Drosophila oogenesis, the mother loads the oocyte with the RNAs and proteins necessary to support embryonic development until zygotic transcription begins $2 \mathrm{hr}$ after fertilization (Gary et al., 1992). However, in Drosophila, the anterior-posterior (AP) patterning system establishes fine-scale pattern through a cascade of transcriptional regulation, beginning with maternally active coordinate genes, through gap genes and pair-rule genes, finally achieving cell by cell resolution at the level of the segment polarity genes (Pankratz and Jäckle 1993). Previous studies showed that the Lissencephaly1 gene has a role in control germ line stem cell (GSC) self-renewal and proliferation (Shuyi et al., 2010). Also, it regulates cyst division, oocyte formation, and oocyte nucleus migration in the Drosophila ovary (Liu et al., 1999; Swan et al., 1999).

A hierarchy of interactions among several classes of genes embryonically controls segmentation in Drosophila. Information is relayed in a temporal progression from the coordinate genes to the gap genes, then from the gap genes to the pair-rule genes and finally, from the pair-rule genes to the segment polarity genes. The even-skipped (eve) gene is considered to be a member of the pair-rule genes. Weak eve mutations (hypomorphs) fit the pair-rule gene criteria, causing deletions of alternate segmentwide regions. Unlike the other pair-rule genes, however, eve null alleles completely abolish segmentation within the trunk of the embryo. Thus, eve appears to be a particularly important member of the pair-rule class of genes (Manoukian and Krause 2016). Mutations in all three of genes were first identified by virtue of their distinctive embryonic phenotypes. When the function of any one of the three genes is re-moved from the embryo, a partial loss of expression of several pair-rule genes occurs; and consequently, some abdominal segments are lost 
or fused together (Wei et al., 2002). The Drosophila lissencephaly (Lis-1) is a homolog of human lissencephaly disease gene and is required for several dynein and microtubule-dependent processes such as germline cell division, oocyte differentiation (Liu $\boldsymbol{e t}$ al., 1999), nuclear migration (Lei and Warrior 2000) and neuroblast proliferation, dendritic elaboration and axonal transport as well as mitotic checkpoint control (Siller et al., 2005). Lis-1 is maternally supplied to embryos and the RNA in situ hybridization revealed the ubiquitous expression during stage 1-3 (Liu et al., 1999) and also stage 4-6, in addition to express in pole cells.

Therefore, the present study aimed to investigate lis-1 gene has a role in axes formation during early embryonic stages through maternal effect or zygotic gene expression. To assess that, the UAS/GAL4 system was used to overexpress RNA interference construct that can suppress the normal function(s) of Lis-1 RNA in early embryonic stages under five GAL4 drivers. The alteration effects on anteriorposterior axis were performed using bicoid (bcd) and even skipped (eve) reading out systems.

\section{Materials and Methods:-}

\section{Drosophila stocks and culture:}

Canton-S (CS) was used as wild-type strain in these experiments. The transgenic RNA interference line for antagonist lis-1 gene; UAS lis-1 RNAi (No. 28663) as well as nanos Gal4 (No. 32563) were obtained from the Bloomington Drosophila Stock Center (http://flystocks.bio. indiana.edu) with a genetic structure ofy ${ }^{1} \mathrm{v}^{1} ; \mathrm{P}\{\mathrm{TRiP} . J F 03078\}$ attP2 and $\mathrm{y}^{1} \quad \mathrm{w}^{*} ; \quad \mathrm{P}\{\mathrm{GAL} 4-$ nos.NGT $\}$ A, respectively. Moreover, a collection of Gal4 drivers (Kni, Nub, Ftz and Eve 3+7 GAL4 with a general formula attP2 (chromosome 3 at 68A4)), which give high expression in early embryonic stages were used to assess the effect of RNA interference to antagonist lis-1 zygotic gene expression in early embryonic stages and its effect on axis formation. These stocks were offered Prof. Dr. Stefan Baumgartner Lab, Dept. of Experimental Medical Science, Section of Developmental Biology, Faculty of Medicine, Lund University, Sweden.

All fly stocks and crosses were maintained and grown on a standard medium of corn meal, agar, yeast, sucrose and propionic acid and supplemented with dried live yeast according to (Ashburner, 1989) at $24 \pm 1{ }^{\circ} \mathrm{C}$ into incubators. Meanwhile, in UAS/GAL4 experiments, the crosses and rearing mainly done on $29^{\circ} \mathrm{C}$ according to (Lawrence $\boldsymbol{e t}$ al., 1994).For analysis of embryonic stages, eggs were collected on apple juice-agar plates(Ostrowski et al., 2002).

\section{Antibodies:}

The primary antibodies: anti-Even-skipped (2B8) from Developmental Studies Hybridoma Bank
(DSHB) as well as Biggin bcd polyclonal antibody (d-200) - from (Santa Cruz Biotechnology) were used at (1:10), (1:500) dilutions, respectively. Secondary antibodies Alexa 488 conjugated goat anti-mouse and Alexa 568 conjugated goat antirabbit (Molecular Probes) and DAPI were used at (1:1000) dilutions for each.

\section{Crosses and miss-expression experiments:}

In this part of study a series of crosses were performed to obtain individuals carrying both GAL4 and UAS lis-1 RNAi line. For this purpose, from each GAL4 driver approximately 15-20 virgin females were crossed to 10 males carrying of UAS lis-1 RNAi line on the third chromosome on separated vials compared to the control as illustrated in (Figure.1).

The crosses were re-reared two times on newly fresh Drosophila medium each three days. Adult flies were collected after eclosion, and then it was incubated at $29^{\circ} \mathrm{C}$ (the maximum tolerable temperature of Drosophila) within 3-4 days before actual egg collecting.

\section{Preparation of Cuticle:}

Crosses between homozygous UAS lis-1 RNAi / GAL4 driver males and females were carried out at $29^{\circ} \mathrm{C}$. After 48 hours on $29^{\circ} \mathrm{C}$, eggs were collected for 2 hour periods and allowed to develop for 24 hours at $29^{\circ} \mathrm{C}$.The obtained embryos were dechorionated in 3-5\% sodium hypochlorite and devitellinized in a heptane/methanol solution to remove their vitelline membranes. Devitellinized embryos were cleared according to (Wieschaus and Nüsslein-Volhard 1986; Lamka et al., 1992) Embryos mounted in Hoyer's medium for 2-3 days at $65^{\circ} \mathrm{C}$. Cuticles phenotypes were analyzed using and photographed using dark-field microscopy (Motic-10 A- China).

\section{Antibody Staining of Embryos:}

For staining of embryos, 0 to 2 hour embryos were obtained and then it were allowed to develop for 3 hours at $29^{\circ} \mathrm{C}$. These embryos were collected and fixed with heat fixation (Muller and Wieschaus 1996). Embryos were rehydrated with PBT (PBS with $0.3 \%$ Triton $\mathrm{X}-100$ ) followed by four washes in PBT. Then the embryo incubated in primary antibody (anti-Even-skipped (2B8) from DSHB (1:10), anti-bcd (d-200) from Santa Cruz Biotechnology) at room temperature for 1 hour on a rotator. After that the primary antibody removed, the embryos rinsed with PBT and the embryos Washed for at least 1 hour at room temperature. While the secondary antibodies (Alexa 488- and Alexa 568conjugated goat anti-mouse, anti-rabbit $(0.6 \mathrm{ml}$ in $600 \mathrm{ml})$ and Add $(1: 1000)$ of DAPI $(1 \mathrm{mg} / \mathrm{ml})$ were added to visualize nuclei, in some cases reaction was needed to diluted in PBT and incubated at room temperature for 1 hour. Moreover the secondary antibodies were removed and the reaction was 
washed at least $4 \times 15$ minutes with PBT at RT. Then embryos were transferred onto slide by using a yellow tip, whose tip had been cut off. Embryos were sucked in and let fall again into the outermost part of the tip, then embryos released onto slide. The surrounding liquid was removed using a Kleenex and 4-5 droplets of $2.5 \%$ DABCO was added and the obtained embryos were dispersed within mounting medium carefully. In the end the slide were covered with a coverslips and metal cubes use to flatten embryos (Patel, 1994).

\section{Statistical analysis:}

Statistical analyses of obtained data were done using chi-square goodness of fit and t test according to McDonald, (2014).
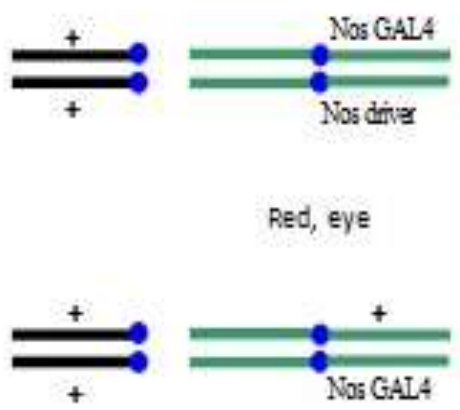

$+$
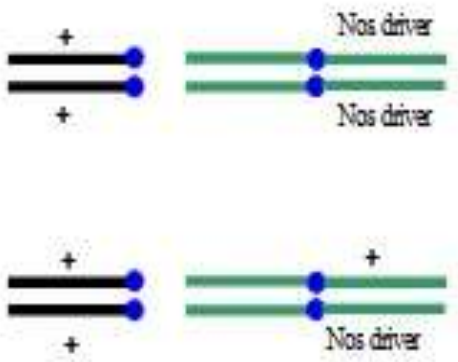
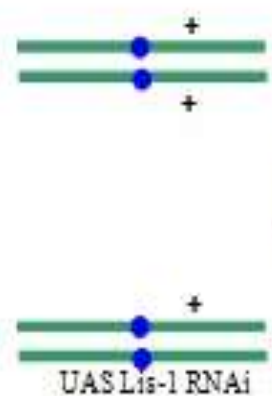

UAS L15-1 RNAi

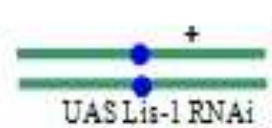

$\mathrm{F} 2$

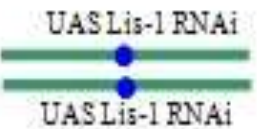

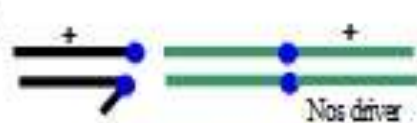
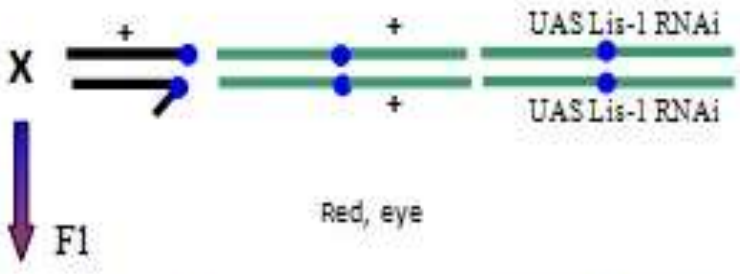

Red, eye
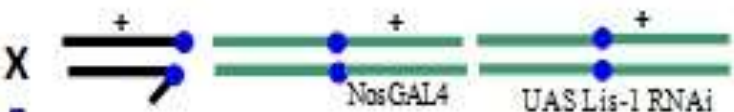

90 desired structure
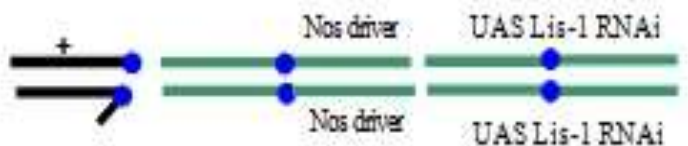

Figure (1): Mating scheme for ectopic expression using UAS / GAl4 system.

\section{Results and Discussion:}

\section{Similarity between Lis-1 Drosophila gene and its counterpart of human homolog}

The Bioinformatics tools revealed high similarity of Drosophila genes and their counterparts of human homolog with high score not only for protein function domains but also for cell biology and developmental functions. In this study we investigated the differential expression of UAS lis-1 $R N A i$ gene. It was examined using UAS/ GAL4 technique, which indicated that this gene may has a role in axis formation. As shown in Table (1), the available information on NCBI for the Lis-1 gene in Drosophila has a similar in human platelet-activating factor acetylhydrolase (PAFAH1B1), which involved in regulation of gene expression. This make Drosophila easier for studying genes that contributed in biological function than human where gene copies can cause redundancy or compensate the defected gene, which may hide the effect of defected gene. Lis-1 gene, is the causative gene for smooth brain, which is a severe congenital brain formation disorder resulting from incomplete neuronal migration during the 12th to 24th weeks of gestation.Lis-1 act with the dynein complex to regulate nuclear migration or cell migration (Liu et al., 1999; Lei and Warrior 2000; Chen et al., 2010). Lis-1 was also identified biochemically in bovine brain extracts as the regulatory subunit a of platelet-activating factor acetylhydrolase, PAFAH, it was shown to be involved in the regulation of neural precursor proliferation and neuronal migration in the developing brain (Hattori et al., 1994; Liu et al., 1999; Chen et al. , 2010). 
Table 2. Available information for axis formation gene on flybase, Ensemble/Homosapiens including, gene name, known function, human homolog and refrence.

\begin{tabular}{|c|c|c|c|c|c|}
\hline Name/GeneID & Location & Description & Location & Reference & function \\
\hline $\begin{array}{l}\text { Lis-1 } \\
\text { ID: } 36791\end{array}$ & $\begin{array}{l}\text { Chromosom } \\
\text { e 2R, } \\
\text { NT_033778. } \\
4 \\
(16178826 . . \\
16185103)\end{array}$ & $\begin{array}{l}\text { Lissencephaly- } \\
1 \text { [Drosophila } \\
\text { melanogaster(fr } \\
\text { uit fly)] }\end{array}$ & $\begin{array}{l}\text { Chromosome } \\
\text { 2R, } \\
\text { NT_033778.4 } \\
(16178826 . .161 \\
85103)\end{array}$ & $\begin{array}{l}\text { (Lei and } \\
\text { Warrior, } \\
\text { 2000). } \\
\text { (Shuyi et al., } \\
\text { 2010). }\end{array}$ & $\begin{array}{l}\text { oocyte axis } \\
\text { specification; mu } \\
\text { scle cell cellular } \\
\text { homeostasis; sen } \\
\text { sory } \\
\text { perception;intrac } \\
\text { ellular mRNA } \\
\text { localizatio }\end{array}$ \\
\hline $\begin{array}{l}\text { PAFAH1B1 } \\
\text { ID: } 5048\end{array}$ & $\begin{array}{l}\text { Chromosom } \\
\text { e } 17, \\
\text { NC_000017. } \\
11 \\
(2593210 . .2 \\
685617)\end{array}$ & $\begin{array}{l}\text { platelet } \\
\text { activating } \\
\text { factor } \\
\text { acetylhydrolase } \\
\text { 1b regulatory } \\
\text { subunit 1 } \\
\text { [Homo } \\
\text { sapiens (human } \\
\text { )] }\end{array}$ & $\begin{array}{l}\text { Chromosome } \\
17, \\
\text { NC_000017.11 } \\
(2593210 . .2685 \\
617)\end{array}$ & $\begin{array}{l}\text { (Lo F et al., } \\
\text { 2012). } \\
\text { (Chen et al., } \\
\text { 2010). }\end{array}$ & $\begin{array}{l}\text { a critical } \\
\text { regulator of } \\
\text { normal and } \\
\text { malignant } \\
\text { hematopoietic } \\
\text { development } \\
\text { regulate } \\
\text { cytoplasmic } \\
\text { dynein motor } \\
\text { activity } \\
\text { regulation of } \\
\text { neural precursor } \\
\text { proliferation and } \\
\text { neuronal migration } \\
\text { in the developing } \\
\text { brain }\end{array}$ \\
\hline
\end{tabular}

\section{Crosses and mis-expression of UAS lis-1 RNAi gene:}

GAL4-UAS system is used to study the expression and function of the UAS lis-1 gene. In this study two hours-old embryos were assembled to know the relationship between the gene under study and the maternal effect genes. Furthermore, embryos more than two hours were collected to study the gene effect on zygotic genes where these genes begin transcript $2 \mathrm{hr}$ after fertilization. After crossbreeding both, the Gal4 driver and the UAS line, the UAS target sequences will be expressed in a spatiotemporal manner (depending on the Gal4 driver used).

The GAL4-UAS system is a binary expression system consisting of two main components: the yeast GAL4 transcriptional activator, expressed in a specific pattern and a transgene under the control of a UAS promoter that is largely silent in the absence of GAL4.GAL4 specifically binds to promoter elements termed upstream activating sequence (UAS), thus activating expression of the downstream target sequence. The GAL4-UASsystem can be used for cell- or tissue-specific genetic mutant rescue, gene over expression, RNAi interference screens and many other applications. This system has been extensively used for developmental studies in tissues such as the central nervous system, retina and muscle (Rodríguez et al., 2012). RNAi lines express short inverted repeat sequences under UAS control. The sequence of the inverted repeat corresponds to an endogenous gene. GAL4-dependent expression of the inverted repeat results in the formation of short hairpin RNAs (shRNAs). The presence of shRNAs initiates a series of cellular mechanisms eventually resulting in silencing of the corresponding endogenous gene by RNA interference (RNAi).Using an inducible short hairpin RNA (shRNA) expressing fly line, the RNAi effect can be activated in a spatio-temporal manner (Prüßing $\boldsymbol{e t}$ al., 2013).

\section{The effect of $U A S$ lis-1 $R N A i$ gene on cuticle preparation:}

In this part of work we investigated the effect of temporal expression of UAS lis-1 RNAi gene on cuticle development. To elucidate the role of lis- 1 in axis formation of Drosophila, series of experiments were done using five GAL4 drivers which works in the same pathway but at a different time (Nos GAL4, Kni GAL4, Nub GAL4, Ftz GAL4 and Eve 3+4 GAL4). Eve3+7 / Lis-1gene showed incomplete fusion of denticle bands between (A4, A5) and (A6, A7) segments, in addition to absent of (A1, A6, A7and A8) segments (Figure 2.B and C). Similar results were obtained under Kni GAL4 driver where it showed complete missing of abdominal segment A1, a partial missing of segment A6 and fusion between (A6, A7) as shown in (Figure 2.D and E).Miss expression of lis-1 under the control of NosGA14 showed missing of (A1, A2, A7, and A8) and partial disappear apart of segment A6 as shown in (Figure 2. F and G). Meanwhile, the expression of UAS Lis-1 RNAi under the effect of Nub GAL4 
showed a deletion of the (A1, A2, A6, A7, A8) abdominal segment and defects of the posterior spiracle (Figure 2. $\mathrm{H}$ and I). On the other hand using Ftz GAL4, the expression of UAS Lis-1 RNAi, showed complete deletion of (A1, A8) as shown in (Figure 2. J). Liu et al., (1999) characterized the Drosophila Lis- 1 and showed that it is essential for fly development. Also, Lei and Warrior, (2000) showed that mutations in the (DLisl) gene result in partial ventralization of the egg shell.
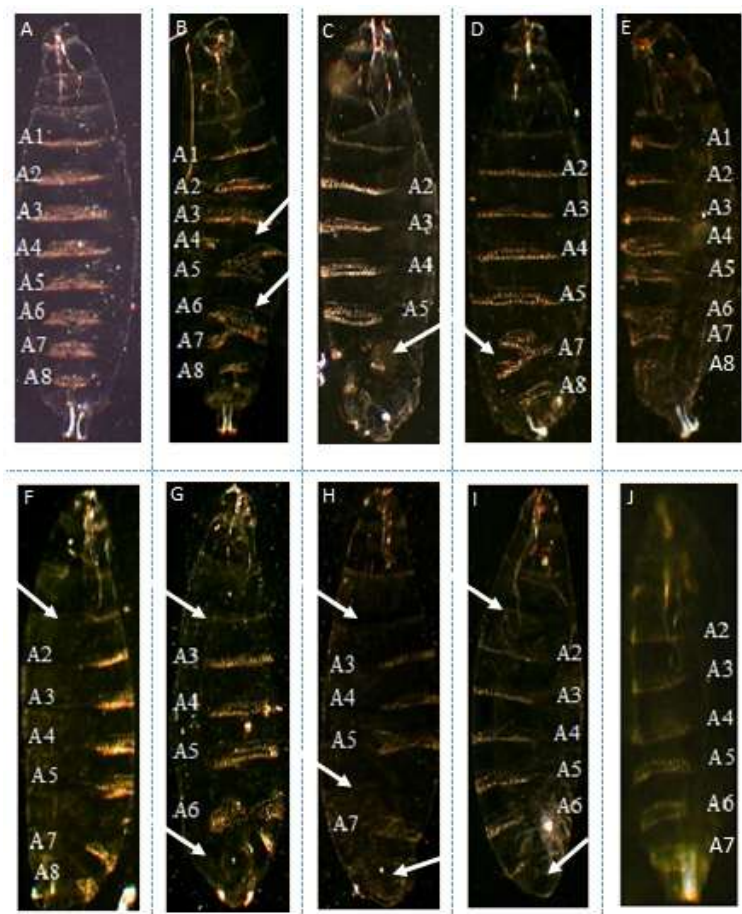

Figure (2): Dark field photographs of cuticle preparations of late wild-type and UAS lislRNAiembryos. (A) Cuticle preparation of a wild-type larva $\mathrm{A} 1$ and $\mathrm{A} 8$ abdominal dentical belts. $(\mathrm{B}, \mathrm{C})$ eve $3+7$ GAL4/ UAS lis-1. (D, E) Kni GAL4/ lis-1 (F, G) Nos GAL4/ UAS lis-1.(H, I) Nub GAL4/ UAS lis-1.(J) Ftz GAL4/ UAS lis-1.

Our results agreed with Poortinga et al., (1998) who found that the cuticle preparations of $\mathrm{dCtBP}$ embryos show segmentation defects, ranging from pair-wise fusions of adjacent denticle bands to more widespread denticle fusions. Loss of maternal $\mathrm{dCtBP}$ in germline mosaics results in severe segmentation defects visualized by cuticle preparations. Similar results for previous studies using pho gene, reported that pho mutant embryos produced from pho females displayed segment defects. Denticle defects occurred in (A1, A2, A5, A4 and A7) segments, suggesting that pho might be involved in segmentation (Kim $\boldsymbol{e t}$ al., 2011).

Chi square test was used to evaluate the significant of interaction between UAS Lis-1 RNAi gene and 5 GAL4 drivers through their effect on abdominal segments pattern. These effects were studied by examining cuticle preparation. Results showed that the statistical analyses of the morphological forms confirmed the expected distribution ratios except (Nub GAL4, Ftz GAL4) where calculated $\mathrm{x}^{2}$ value was greater than tabulated $\mathrm{x}^{2}$.The obtained chi square values were significant at the $0.05 / 3.84$ level $(\mathrm{p}=0.01 / 6.64)$ with embryos carrying Nos, Kni and Eve 3+4 GAL4drivers except for with Nub, Ftz GAL4 drivers where the values were $(9.6,31.7)$,non-significant, this is due to the limited number of deformed embryos.

The effect of UAS lis-1 RNAi gene on segmentation pattern of drosophila development:

The process of segmentation is initiated by gradients of maternal gene products such as bicoid (bcd) and nanos (nos), which establish anteriorposterior polarity and specify positional information based on their concentration (Driever, 1993).In this part of the study, we used Nos GAL4 to identify the effect of UAS lis-1 RNAi gene expression on bicoid and even-skipped expression. From data base, Nos GAL4 expressed from 0-2 hours as well as temporal expression of UAS lis-1 RNAi gene is high from 0-2 hours and moderately high expression from 4-10 hours (http://flystocks.bio.indiana.edu).

Effects of UAS lis-1 RNAi on eve-skipped and bicoid expression:

During the first 20 minutes of cycle 14, a sevenstripe pattern of eve expression is formed (Kosman and Small 1997). These stripes appear in a particular temporal order, suggesting that the initiation of each stripe depends on a different mechanism. Eve is expressed in a seven-stripe pattern in wild type embryos as shown in (Fig. 3.A). The ectopic expression of UAS lis-1 RNAi, mutant embryos showed abnormal eve stripe patterns including increasing in the length of head area and the distance between the second and the third stripe and causes only a weak repression of eve7stripe as shown in (Fig. 3. B). On the other hand, the width of stripe patterns increased so the space between them considered narrow as shown in (Fig. 3. C) and partial disappear of 5 stripe as shown in (Fig. 3. D).Meanwhile these phenotypes demonstrated that stripe was extended especially of 1stripe patterns whereas mis-expression of UAS Lis-1 RNAi caused weaker ventral repression of (2, 6 and 7) eve stripes and the distance between 4 and 5 stripe was increased as shown in (Fig. 3. E). Mis-expression of UAS Lis-1 RNAi illustrated expansion of eve stripe were observed in the posterior region of the embryo except stripe 3 comparing with control and causes only a weak repression of eve 2 and 7 stripes as shown in (Fig. 3. F).Low levels of ectopic UAS lis-1 $R N A i$ cause reduction of 2 and 5stripe eve expression (Fig. 3.E, B, and D). Results revealed a strong correlation between levels of ectopic UAS lis-1 RNAi and eve stripe pattern. 

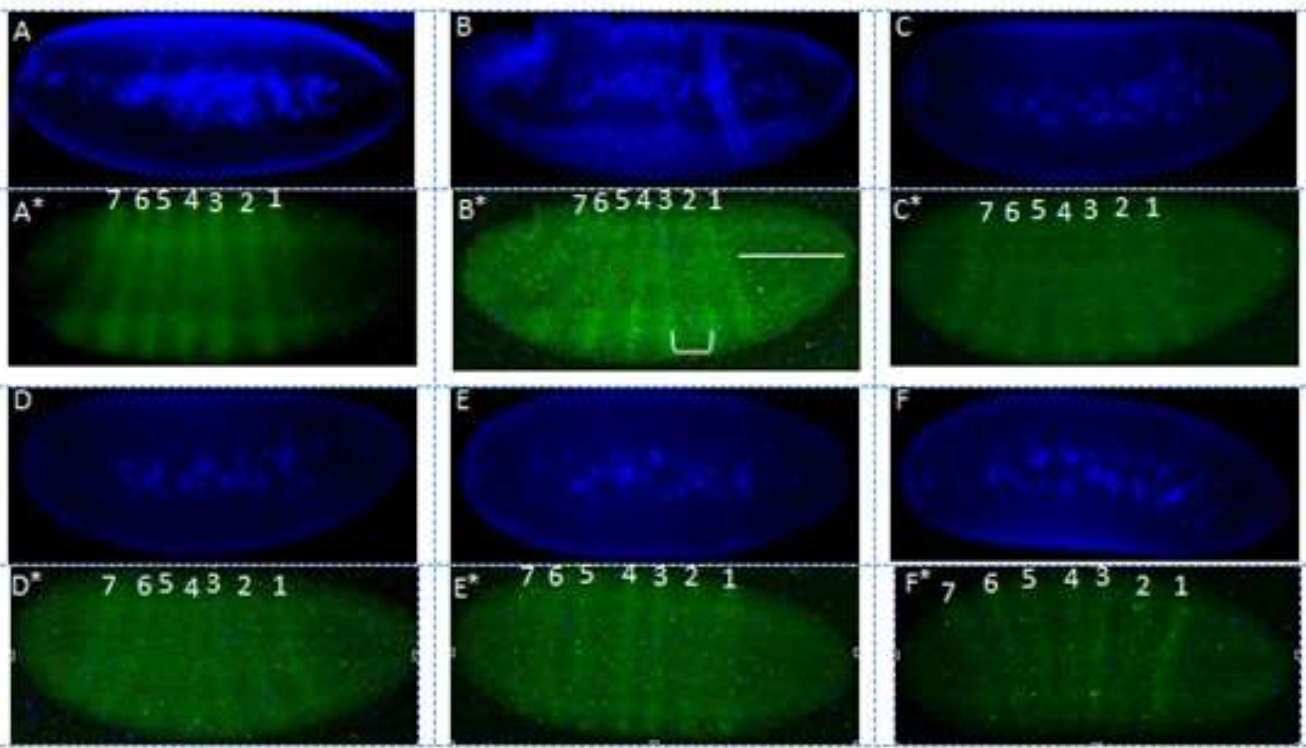

Figure (3) : ( A) Eveis expressed in a seven-stripe pattern in wild type embryo.(B-F)Nos GAL4/UAS lisIRNAi, Effects of ectopic Lissencephaly-1expressionon the eve striped pattern.

Similar results were obtained from Kosman and Small, (1997) studies of kni mutant embryos, and its effect on eve expression, where it indicated that the intermediate levels delay in stripe 3 initiation and completely abolished of eve stripe 3 in another embryo.

Our results agreed with (Kwong et al.,2008) who found that the eve is expressed in a seven-stripe pattern in wild type embryos but in pho mutant embryos, its expression were partially extended or even fused within each other's stripe, suggesting that Pho negatively regulates eve expression.

Similar results for previous studies of Slp1 expression was illustrated that alone distorts the expression of eve 1 in ventral regions, and causes a strong repression of eve 2 and a weaker repression of eve3. The repressive effects of ectopic Slp1 on the three anterior eve stripes suggest a common mechanism for repression in anterior regions of the embryo. By contrast, ventrally mis-expressed Gt causes only a weak repression of eve1 and 2, but strongly affects eve5, a repression target of the posterior Gt gene expression domain (Luiz et al., 2002).

In this study, we used Anti-Bcd antibody to know the effect of $U A S$ lis-1 RNAi on the distribution of bicoid protein. The expression of UAS lis-1 RNAi enhanced gene silencing (Fig. 4.B.C), where the distribution of bicoid protein was lower than control as shown in (Fig. 4.A).that reflected efficient repression of Lis1 mRNA and decreased the normal function of this gene.
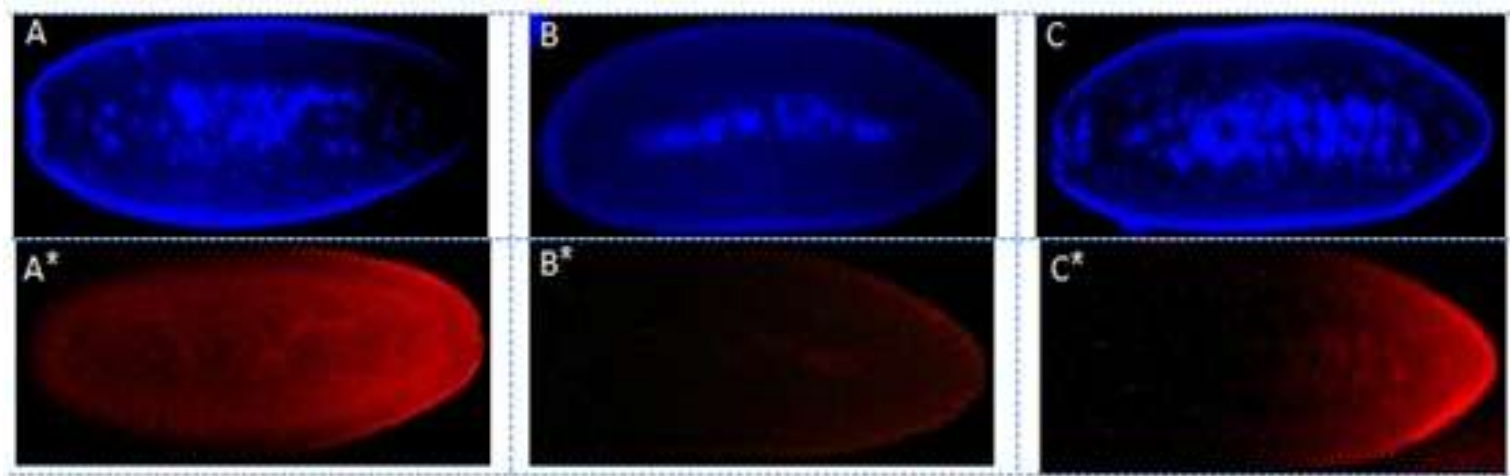

Figure (4): Bcd protein distributions in pre-cellular embryos. Anti-Bcd antibody detected bcd protein (red fluorescence).(A) wild type embryos.(B,C)Nos GAL4/UAS lis-1RNAi.

The Bicoid (bcd) protein gradient is generally believed to be established in pre-blastoderm drosophila embryos by the diffusion of bed protein after translation of maternal mRNA, which serves as a strictly localized source of bcd at the anterior pole (Spirov et al., 2009). Whether the bcd protein gradient forms by passive diffusion following synthesis of this protein at more anterior locations (Gregor et al., 2007; Little et al., 2011), based on bcd mRNA concentration gradient (Fahmy et al., 2014; Spirov et al., 2009). Finally, these finding suggest that Lis-1misexpressedgene using even 
skipped antibody might repress the expression of eve gene as one of the pair-rule genes indicating the important of this protein in axis formation. Also, our results show that bicoid mRNA localization is a multi-step process, and that redundant mechanisms are used to ensure the anterior accumulation of bicoid mRNA.

\section{Conclusion}

The obtained results indicated that Drosophila melanogaster model system is very useful for studying biological pattern formation and body plan scaling. Results for cuticle preparations of embryos carrying UAS lis-1 RNAi gene construct under the effect of Nos GAL4, Nub GAL4, Eve 3+7 GALA, Kni GAL4, Ftz GAL4 drivers exhibited segmentation defects, ranging from pair-wise fusions of adjacent denticle bands and missing of abdominal denticle belts suggests that UAS lis-1 RNAi might function in segmentation. These results imply that Lis-1 proteins might be involved in regulating the expression of segmentation genes. However, these finding suggest that mis-expressionofLis-1mutation using even skipped antibody might repress the expression of pair-rule genes especially even gene, indicating the important of the protein in axis formation. Our results suggested that the UAS Lis-1 RNAi is required in Drosophila anterior-posterior axis formation.

Bicoid protein gradient controls the hierarchy of segmentation genes at beginning of embryogenesis. The mis-localization of bicoid mRNA in embryos resulted from UAS Lis-1 RNAi disturbs this gradient, resulting in level distribution. Thus, our results show that bicoid mRNA localization is a multi-step process, and that redundant mechanisms are used to ensure the anterior accumulation of bicoid mRNA.

\section{Acknowledgements}

The authors thank Dr. S. Baumgartner, Sc. Developmental Biology, Dept. of Experimental medical science, Lund University for facilities. We would like to thank Developmental Studies Hybridoma Bank/The University of Iowa for antibodies.

\section{References}

Adams, M. D.; Celniker, E. S.; Holl, A. R.; Evans, C. A.; Gocayne, J. D. and Amanatides, P. G. (2000). The Genome sequence of Drosophila melanogaster: Sci. 287: 2185-2195.

Ashburner, M. (1989). Balancers and other special chromosomes, in Drosophila-A Laboratory Manual (Ashburner, M., ed.) Cold Spring Harbor Laboratory Press, Cold Spring Harbor, NY. 2:529-548.
Brand, A. and Perrimon, N. (1993).Targeted gene expression as a means of altering cell fates and generating dominant phenotypes. Development. 118 (2): 401-415.

Chen, S.; Kaneko, S.; Ma, X.; Chen, X.; Tony, I. Y.; Xu, L. and Xie, T. (2010).Lissencephaly1controls germline stem cell self-renewal through modulating bone morphogenetic protein signaling and niche adhesion. Developmental Biology, 107 46:19939-19944.

Driever, W. (1993). Maternal control of anterior development in the Drosophila embryo. In The Development of Drosophila melanogaster. (ed. M. Bate and A. Martinez Arias). pp. 301-324. Cold Spring Harbor Laboratory Press.

Fahmy, K.; Akber, M.; Cai, X.; Koul, A.; Hayder, A. and Baumgartner, S. ( 2014). ATubulin 67C and Ncd are essential for establishing a cortical microtubular network and formation of the bicoid mRNA gradient in Drosophila. 9:e112053. . PLoS one, 9 (11):1-11.

Gary, S.; Johnston, P. and Lawrence, P. A. (1992). Control of Drosophila body pattern by the hunchback morphogen gradient. 69 (2): 237249.

Gregor, T.; Wieschaus, E. F.; Gregor, A. P.; Bialek, W. and Tank, D. W. (2007). Stability and nuclear dynamics of the Bicoidmorphogen gradient. Cell, 130: 141-152.

Hattori, M.; Adachi, H.; Tsujimoto, M.; Arai, H. and Inoue, K. (1994). Miller-Dieker lissencephaly gene encodes a subunit of brain platelet activating factor acetylhydrolase [corrected] [published erratum appears in Nature 1994 Aug 4; 370 (6488):391]. Nature, 370: 216218.

Kim, N. S.; Shim, P. H.; Jeon, B.; Choi, W.; Hur, M.; Girton, R. J.; Kim, H. S. and Jeon, S. (2011). The Pleiohomeotic Functions as a Negative Regulator of Drosophila even-skipped Gene during Embryogenesis. Mol. Cells 32: 549554.

Kosman, D. and Small, S. (1997). Concentrationdependent patterning by an ectopic expression domain of the Drosophila gap gene knirps. Development 124: 1343-1354.

Kwong, C.; Adryan, B.; Bell, I.; Meadows, L.; Russell, S.; Manak, J. R. and White, R. (2008). Stability and dynamics of polycomb target sites in Drosophila development. PLos Genet. 4:1-15.

Lamka, M. L.; Boulet, A. M. and Sakonju, S. (1992). Ectopic expression of UBX and ABD-B proteins during Drosophila embryogenesis: Competition, not a functional hierarchy, explains phenotypic suppression. Development 116:841854.

Lawrence, S. B.; Goldstein, A. and Fyrberg, E. (1994). Drosophila melanogaster: Practical uses in 
cell and molecular biology. Academic Press, 44: 14-31.

Lei, Y. and Warrior, R. (2000). The Drosophila Lissencephaly1 (DLis1) Gene is required for Nuclear Migration. Developmental Biology 226: 57-72.

Little, S. C.; Tkacik, G.; Kneel, B. T.; Wieschaus, F. E. and Gregor, T. (2011). The formation of the Bicoid morphogen gradient requires protein movement from anteriorly localized mRNA. PLoS Biology, 9 (3):1-17.

Liu, Z.; Xie, T. and Steward, R. (1999). Lis1, the Drosophila homolog of a human Lissencephaly disease gene, is required for germline cell division and oocyte differentiation. Development 126:4477-4488.

LoF, Y.; Chen, H. T.; Cheng, H. C.; Hsu, H. S. and Wang, Y. C. (2012). Over expression of PAFAH1B1 is associated with tumor metastasis and poor survival in non-small cell lung cancer. 77 (3): 585-592.

Luiz, M. A.; Vasisht, V.; Theodosopoulou, E.; Oberstein, A. and Small, S. (2002). Anterior repression of a Drosophila stripe enhancer requires three position-specific mechanisms. Development 129: 4931-4940.

Manoukian, S. A. and Krause, M. H. (2016).Concentration-dependent activities of the even-skipped protein in Drosophila embryos. Cold Spring Harbor Laboratory Press 6:17401751.

McDonald, J. H. (2014). Handbook of Biological Statistics, 3rd ed. Sparky House Publishing, Baltimore, Maryland.

Muller, H. A. and Wieschaus, E. (1996). Armadillo, bazooka, and stardust are critical for early stages in formation of the zonulaadherens and maintenance of the polarized blastoderm epithelium in Drosophila. Cell Biol, 134(1): 149163.

Ostrowski, S.; Dierick, H. A. and Bejsovec, A. (2002).Genetic Control of Cuticle Formation during Embryonic Development of Drosophila melanogaster. Genetics161:171-182.

Pankratz, M. J. and Jäckle, H. (1993). The Development of Drosophila melanogaster. Cold Spring Harbor, NY: Cold Spring Harbor Laboratory. Biol.44:445-487.

Patel, N. H. (1994). Imaging neuronal subsets and other cell types in whole-mount Drosophila embryos and larvae using antibody probes. Methods Cell Biology, (ed. L. S. B. Goldstein and E. A. Fyrberg ) , pp.445-487.SanDiego: Academic Press..

Poortinga, G.; Watanabe, M. and Parkhurst, M. S. (1998). Drosophila CtBP: a Hairy-interacting protein required for embryonic segmentation and Hairy-mediated transcriptional repression. The EMBO 17.7 2067-2078.
Prüßing, K.; Voigt, A. and Schulz, B. J. (2013). Drosophila melanogaster as a model organism for Alzheimer's disease. Molecular

Neurodegeneration, 22:8-35.

Rodríguez d. A., Didiano D. and Desplan C. (2012). Power tools for gene expression and Clonal analysis in Drosophila. Nature methods 9:47-55.

Rubin, G. M.; Yandell, M. D.; Wortman, J. R.; Gabor, M. G.; Nelson, C. R.; Hariharan, I. K.; Fortini, M. E.; Li, A. R. and Fleischmann, W. (2000). Comparative genomics of the eukaryotes. Science, 287:2204-2215.

Shuyi, C.; Kaneko, S.; Ma, X.; Chen, X.; Tony, Y. I.; Xu, L. and Xie, T. (2010).Lissencephaly1 controls germline stem cell self-renewal through modulating bone morphogenetic protein signaling and niche adhesion developmental biology pnas. vol. 107| no. 46:19939-19944.

Siller, K. H.; Serr, M.; Steward, R.; Hays, T. S. and Doe, C.Q. (2005). Live imaging of Drosophila brain neuroblasts reveals a role for Lis1/dynactin in spindle assembly and mitotic checkpoint control. Mol. Biol. Cell. 16:51275140. http://dx.doi.org/10.1091/mbc.E05-040338.

Spirov, A.; Fahmy, K.; Schneider, M.; Frei, E.; Noll, M. and Baumgartner, S. (2009). Formation of the Bicoid morphogen gradient: an mRNA gradient dictates the protein gradient. Development, 136:605-614.

Swan, A.; Nguyen, T. and Suter, B. (1999). Drosophila Lissencephaly-1 functions with Bic-D and dynein in oocyte determination and nuclear positioning. Nat Cell Biol1, 444-449.

Umulis, D. M. and Othmer, H. G. (2013). Mechanisms of scaling in pattern formation. Development 140:4830-4843.

Wei, C. H.; Chen, X.; Wan, S.; Marinissen, M.; Gutkind, S. J. and Hou, X. S. (2002). Mom identifies a receptor for the Drosophila JAK/STAT signal transduction pathway and encodes a protein distantly related to the mammalian cytokine receptor family. Genes Development, 16: 388-398.

Wieschaus, E. and Volhard, C. N. (1986). Looking at embryos. In Roberts D.B., ed. Drosophila: A Practical Approach. Washington, DC, IRL Press: 199-227.88aa. 